\title{
Síndrome de burnout e projeto de ser
}

\author{
Fernando Gastal de Castro ${ }^{1}$ e José Carlos Zanelli $^{2}$ \\ Departamento de Psicologia da Universidade Federal de Santa Catarina
}

\begin{abstract}
O esgotamento físico e emocional em função do trabalho tem se tornado uma situação cada vez mais comum dentro das organizações nos dias atuais. Desde a década de setenta ele tem sido definido como síndrome de burnout. Seus pesquisadores têm sustentado que burnout se desenvolve como uma resposta aos estressores crônicos presentes nas organizações de trabalho. Porém, o estado atual do conhecimento sobre o processo de desenvolvimento de burnout tem se evidenciado, para muitos, como um problema teórico ainda não resolvido. $\mathrm{Na}$ busca de compreender tal processo, que se inicia com a experiência de estresse crônico e chega à exaustão, a despersonalização e a diminuição da realização pessoal, uma variável importante no conjunto desse fenômeno não tem recebido um tratamento científico adequado, qual seja: a relação do profissional com seu projeto para o futuro ou, mais precisamente, a relação do profissional com o fracasso do futuro projetado. A partir da utilização da definição de projeto de ser de Sartre, buscou-se evidenciar a relevância de se articular teoricamente a definição de projeto de ser com o processo de desenvolvimento da síndrome de burnout, para um avanço na compreensão desse fenômeno complexo.
\end{abstract}

Palavras-chave: Burnout, Projeto de ser, Existencialismo, Significado do trabalho e Síndrome de burnout.

Syndrome of burnout and project of being

The physical and emotional exhaustion related to work has become a more and more frequent problem inside organizations. Since the seventy's it has been defined as burnout syndrome. Its researchers have supported that burnout syndrome develops as one answer to chronic stressors existing in work organizations. However, the current state of knowledge about the burnout syndrome process of development has been evidenced for many as a theoretical problem not yet solved. In the quest for understanding this process, that initiates with the experience of the chronic stress and leads to emotional exhaustion, despersonalization and reduced personal accomplishment, a variable regularly present in this process has not been given scientific treatment, which mean: the relation of the professional with his project for the future, more precisely, the relation of this professional with the failure of the projected future. The use of the definition project of being of Sartre will search to evidence the relevance to theoretically articulate the definition project of being with the process of development of the burnout syndrome for the advance of the comprehension of this complex phenomenon.

Keywords: Burnout, Project of being, Existentialism, Meaning of labor.

\section{A definição da síndrome de burnout}

$\mathrm{N}$ a década de setenta, ao investigar a carga emocional do trabalho de enfermeiros, médicos, assistentes sociais e advogados, Maslach (1993) constatou que a expressão "burn out" (ser consumido, queimado pelo trabalho) era em geral usada para expressar uma exaustão emocional gradual, um cinismo e a ausência de comprometimento experimentado em função das altas demandas de trabalho. Dessa maneira, Maslach (1978), em convergências com as observações clínicas de Freudenberger (1974), chegou a descoberta de burnout como sendo uma "síndrome psicológica decorrente da tensão emocional crônica, vivida pelos profissionais cujo trabalho envolve o relacionamento intenso e freqüente com pessoas que necessitam de cuidado e/ou assistência" (Seligmann-Silva, 1996, p. 46).

1 Doutorando do Programa de Pós-Graduação em Psicologia do Departamento de Psicologia da Universidade Federal de Santa Catarina.

2 Doutor em Psicologia, professor e pesquisador do Departamento de Psicologia da Universidade Federal de Santa Catarina. 
Baseando-se nessas investigações exploratórias de Maslach (1978) e de Freudenberger (1974) é possível afirmar que a definição da síndrome de burnout é multidimensional, ou seja, compreende um conjunto de três variáveis ou dimensões essenciais que especificam e demarcam tal fenômeno, quais sejam: a exaustão emocional (EE), a despersonalização (D) e a diminuição da realização pessoal (DRP). A variável exaustão emocional (EE) é caracteriza pelo fato da pessoa encontrar-se exaurida, esgotada, sem energia para enfrentar um outro projeto, as outras pessoas e incapaz de recuperar-se de um dia para o outro (Maslach, Shaufeli \& Leiter, 2001). Seus indicadores, conforme descritos por Maslach e Jackson (1981), evidenciam, desse modo, a experimentação psicofísica do indivíduo no limite de suas forças. A variável despersonalização (D) é caracterizada pelo fato da pessoa adotar atitudes de descrença, distância, frieza e indiferença em relação ao trabalho e aos colegas de trabalho (Maslach, Shaufeli \& Leiter, 2001). A despersonalização evidencia, nesse sentido, que burnout não é somente a síndrome do profissional exausto, mas também do profissional indiferente e descomprometido em relação às pessoas com quem trabalha. Por fim, A variável diminuição da realização pessoal (DRP) é caracterizada pelo fato da pessoa experimentar-se ineficiente, incapaz e certa de que seu trabalho não faz diferença (Maslach, Shaufeli \& Leiter, 2001). O que permite concluir que burnout é a síndrome do profissional frustrado, descomprometido com os outros e exaurido emocionalmente. Benevides-Pereira (2002), Maslach, Shaufeli e Leiter (2001) e Shaufeli e Bunnk (2003), além de confirmarem a definição de burnout como constituída essencialmente por EE, D, DRP, têm descrito também, uma série de sintomas físicos e emocionais comumente relacionados à síndrome: dores de cabeça, tensão muscular, distúrbios do sono, irritabilidade, sentimentos negativos que começam a afetar o relacionamento familiar e a vida em geral, propensão a largar o emprego e absenteísmo.

Essa definição do fenômeno de burnout vem sendo confirmada por investigações que atestam a coesão entre as três variáveis constitutivas da síndrome e suas relações com estressores laborais. Um importante estudo nesse sentido é a análise de Lee e Ashfort (1996) que investiga a correlação entre as três variáveis de burnout e suas relações com altas demandas de trabalho e baixos recursos. Os autores analisam estudos empíricos realizados entre 1982 e 1994 que se utilizaram da definição multidimensional de Maslach e Jackson (1981) a respeito de burnout e buscam, dessa forma, confirmar as correlações entre as três variáveis e os estressores ligados ao trabalho. Lee a Ashfort (1996) concluem que o conjunto dos estudos empíricos realizados no período a respeito da síndrome de burnout confirmam a natureza multidimensional do fenômeno, verificando que a variável exaustão emocional aparece regularmente correlacionada a altas demandas de trabalho (sobrecarga, pressão de tempo, conflitos e ambigüidade de papel profissional) e que as variáveis despersonalização e diminuição da realização pessoal aparecem regularmente correlacionadas a baixos recursos (baixa autonomia e poder de decisão e falta de suporte de colegas e chefias).

Sete anos após a publicação dessa meta-análise de Lee e Ashfort, Shaufeli e Bunnk (2003) publicam um estudo sobre o estado da arte a respeito de burnout e, da mesma forma, confirmam a definição de burnout como constituída pelas mesmas três variáveis essenciais (EE, D, DRP) e distinta dos demais fenômenos ligados ao trabalho, tais como o estresse profissional e a fadiga crônica. Demonstram, dessa forma, que burnout não é apenas "um velho vinho em uma nova garrafa" (Shaufeli \& Bunnk, 2003, p. 390) e deixam claro que só é possível compreender tal fenômeno levando-se em consideração a relação das três variáveis entre si e suas correlações com os estressores organizacionais que as determinam.

A partir dessa definição da síndrome de burnout, um fenômeno multidimensional constituído por suas três variáveis fundamentais (EE, D e DRP), faz-se necessário demarcar o conjunto de estressores presentes na realidade do trabalho e das organizações que estão correlacionadas ao desencadeamento de burnout. Maslach e Leiter (1997) e Maslach, Leiter e Shaufeli (2001) especificam o seguinte conjunto de ocorrências estressoras: aquelas 
relacionadas às altas demandas de trabalho e aquelas relacionadas a poucos recursos. Em relação às altas demandas, são especificadas as seguintes ocorrências: aumento da carga de trabalho, caracterizada pelo fato de menos pessoas estarem fazendo mais trabalho; pressão de tempo, caracterizada pela fato de o tempo não ser suficiente para cumprir as exigências de trabalho; aumento da complexidade do trabalho, caracterizada pelo fato de um mesmo profissional desempenhar múltiplas funções simultaneamente; papel conflitante, caracterizado pela obrigação profissional de executar funções contrárias e conflituosas; e por último, a ambigüidade de papéis, decorrentes de informações inadequadas e ambíguas ao comprimento da função profissional.

Em relação ao conjunto de estressores relacionados a poucos recursos são especificados os seguintes: falta de suporte no trabalho por parte de supervisores, que deixa o profissional sem uma chefia que dê apoio para o enfrentamento e a resolução dos problemas de trabalho; falta de suporte de colegas, caracterizada pela perda da confiança no trabalho de equipe criando relações de competição e isolamento entre os profissionais; falta de controle e autonomia sobre dimensões importantes de suas atividades profissionais que impede os profissionais de resolverem os problemas relacionados ao seu trabalho e falta de recompensa material caracterizada pela redução de salários e benefícios e por menos oportunidades de progresso na carreira. Shaufeli e Buunk (2003), ao fazer o estado da arte sobre o fenômeno de burnout, confirmam o mesmo conjunto de estressores laborais relacionados ao desencadeamento de burnout, dando especial destaque para sobrecarga, pressão de tempo, conflito de papel e falta de suporte, como àqueles correlacionados mais significativamente com os sintomas da síndrome. Jardim, Silva Filho e Ramos (2004) - ao realizar uma revisão da literatura sobre a síndrome de burnout em livros, dissertações e teses no plano internacional publicados entre os anos de 1980 e 2001 - confirmam a prevalência de burnout em profissionais da área de serviços de assistência (professores, profissionais da saúde, policiais, assistentes sociais, advogados etc.). E, em corroboração com Maslach, Shaufeli e Leiter (2001), verificam que os estressores mais importantes presentes na organização de trabalho que predispõe os trabalhadores a síndrome de burnout são: o papel conflitante, a perda de controle ou autonomia sobre seu fazer, a ausência de suporte social e a sobrecarga.

Em síntese, a síndrome de burnout não se reduz à exaustão física e emocional resultante da alta sobrecarga de trabalho. Evidenciam-se além disso, estressores de ordem interpessoal (falta de suporte) e também estressores relativos às interferências burocráticas (conflitos e ambigüidade de papel e falta de autonomia) que, ao atuarem em conjunto, tiram do indivíduo a sua condição de sujeito capaz de realizar bem seu trabalho, bem como, de realizar-se através do trabalho que executa. Para compreender o fenômeno de burnout, portanto, é necessário situar o indivíduo dentro desse conjunto de estressores laborais que, por sua vez, evidenciam uma determinada dinâmica de funcionamento das organizações de trabalho em o indivíduo está inserido, caracterizada por uma burocracia profissional (Winnubst, 1993) que e impessoaliza o trabalho (Freudenerguer, 1987) e aliena o indivíduo.

\section{O processo de desenvolvimento de burnout}

A exposição realizada até aqui define o fenômeno de burnout como algo já constituído, demarcado por um conjunto de variáveis estressoras laborais correlacionadas à síndrome, mas não permite compreender o seu processo de desenvolvimento. Nesse sentido é que Maslach e Leiter (1997) e Maslach, Shaufeli e Leiter (2001) sustentam a necessidade de esclarecer o processo que leva os sujeitos com alto comprometimento e motivação a desenvolverem um quadro de burnout. E, da mesma forma, Taris, Le Blanc, Shaufeli e Schreurs (2005) afirmam que a síndrome de burnout precisa ser compreendida como um 
processo de desenvolvimento e salientam como a estrutura desse processo ainda é largamente desconhecida. De sorte que, ao abordar o processo de desenvolvimento de burnout, constatase o seguinte problema: o de compreender como certos profissionais que ao início de suas carreiras encontram-se repletos de desejos a realizar, expectativas, ideais, comprometidos e motivados com o que fazem, tornam-se ao longo do tempo, exaustos, frustrados e descomprometidos. A hipótese teórica sustentada por Benevides-Pereira (2002), Gil-Monte (2003), Gil-Monte e Peiró (1999), Lee a Ashfort (1996), Leiter (1993), Maslach, Shaufeli e Leiter (2001), Shaufeli e Bunnk (2003) e Tamayo e Tróccolli (2002) é que burnout se desenvolve como uma resposta aos estressores crônicos laborais. Porém, como esses estressores laborais crônicos podem levar certos indivíduos a padecerem de um quadro como o de burnout? Em outros termos: como a relação constante e diária do profissional com as altas demandas e os pouco recursos no âmbito organizacional pode desenvolver um quadro psicológico de exaustão, despersonalização e frustração?

O balanço da literatura sobre o fenômeno de burnout realizado por Jardim, Silva Filho e Ramos (2004), abrangendo os últimos vinte anos de pesquisas sobre o problema, deixa evidenciado que os profissionais que desenvolvem a síndrome de burnout são justamente "aqueles que mais se dedicam a um projeto, que investem totalmente em seu trabalho, mais identificados com os ideais da ocupação e da profissão que ocupam" (Jardim, Silva filho \& Ramos, 2004, p. 83). Dessa forma, um fato regularmente verificado pelas pesquisas empíricas sobre o fenômeno de burnout nos últimos vinte anos é que os profissionais desejam alcançar um futuro para si próprios através da profissão que exercem e desenvolvem a síndrome quando começam a experimentar fracassos e desilusões relativos a seus projetos futuros. Essa constatação é possível encontrar também nos trabalhos de Codo (1999) e Farber (1984) ao estudarem o fenômeno de burnout nos professores, quando observam como a perda do idealismo, característico dessa categoria profissional, gera um processo em que o indivíduo vai desiludindo-se, fechando-se sobre si mesmo e perdendo o interesse pelo trabalho e pelo mundo e assim desenvolvendo burnout. Da mesma forma, Freudenberger (1974) afirma que "burnout ocorre como conseqüência da perda de um ideal" (p. 165) e Aubert (2001) observa que, quando "o processo de desilusão, ou antes, de 'desidealização', está iniciado a queimadura interna começa” (p. 191). E ainda Cherniss (1995) ao verificar que, quando os fortes ideais e altas expectativas que os profissionais tinham ao início de suas carreiras são perdidos, os indivíduos são levados a uma diminuição drástica da realização pessoal que exaure suas forças. E, por fim, cabe ainda fazer remissão a Maslach, Shaufeli e Leiter (2001) quando postulam que a síndrome de burnout se desenvolve em função de um desequilíbrio entre os valores individuais almejados pelos sujeitos e a realidade organizacional na qual não encontram lugar. É possível concluir, a partir dessas constatações, que as pessoas que desenvolvem burnout são pessoas engajadas com um futuro profissional e comprometidos com certos valores que desejam pôr em prática e, justamente, o fracasso e a perda desse futuro gera desilusão e uma conseqüente perda do comprometimento, dando lugar à sintomatologia de burnout.

Apesar do sentimento de desilusão e fracasso em relação ao futuro profissional esperado e desejado pelo indivíduo estar sempre presente na gênese do processo de desenvolvimento de burnout, como corroboram Pines (1993) e Carllotto (2002), não é possível encontrar, ao revisar os modelos teóricos que tratam de compreender seu processo de desenvolvimento, um tratamento teórico que considere essa dimensão do homem com seu futuro como uma variável chave para se compreender o processo de desenvolvimento do fenômeno em questão. Com o objetivo de dar mais visibilidade e sustentação a essa questão, serão considerados a seguir os modelos teóricos de Maslach $(1978,1993)$, Shaufeli e Buunk (1993, 2003), Cherniss (1993), Gil-Monte e Peiró (1999) e, por fim, Pines e Aronson (1988).

Maslach, Leiter e Shaufeli (2001) sustentam que o processo de desenvolvimento de burnout é uma resposta ao estresse crônico vivido no trabalho, levando o indivíduo à exaustão 
emocional e, como uma estratégia de defesa, ele passa a tratar as pessoas com quem trabalha com frieza, cinismo e desprezo, o que, por sua vez, diminui a realização pessoal, constituindose, desse modo, um quadro de burnout. A variável chave para compreender o desenvolvimento da síndrome de burnout, nesse sentido, seria a exaustão emocional (Maslach, 1978), uma vez que, dela dependeria o desenvolvimento das variáveis despersonalização e diminuição da realização pessoal. Mas, com base nessa tese, como ocorre do indivíduo passar do estresse crônico no trabalho e chagar ao esgotamento emocional?

Maslach (1978) centra sua análise na relação do profissional com as pessoas (clientes, pacientes, alunos etc.) a quem presta assistência como a principal fonte de estresse e potencialmente capaz de levar ao esgotamento emocional. Considera que a maior fonte de motivação que leva os sujeitos a escolher profissões que prestam assistência seria fazer a vida das pessoas mais feliz e saudável, ou seja: "trabalhar com pessoas e ajudá-las de alguma maneira foi sua principal razão para entrar em sua profissão e é frequentemente a primeira fonte de satisfação em seu trabalho" (p. 120). Desse modo, o foco de trabalho dos profissionais que prestam assistência está nos problemas das pessoas que precisam ser resolvidos, o que os faz estarem envolvidos em relações potencialmente estressantes continuamente. E, à medida que os profissionais nas organizações de assistência encontramse envolvidos com alta sobrecarga de trabalho (ao terem que fazer muito em pouco tempo e com poucos recursos) e tendo que enfrentar clientes insatisfeitos, que não têm suas necessidades atendidas, essa alta sobrecarga e a falta de feedback positivo tornam-se uma fonte de insatisfação, desilusão e sofrimento psicológico (Maslach, 1978) capaz de levar as pessoas à exaustão emocional e conseqüentemente a burnout. Portanto, verificando os argumentos de Maslach, é possível observar que o processo que vai do estresse crônico ao esgotamento emocional passa por experimentações de insatisfação, desilusão e sofrimento psicológico em função do fracasso em promover, pelo seu trabalho, melhores condições de vida para as pessoas assistidas.

No entanto, não é possível encontrar no modelo teórico de Maslach (1993) e Maslach e Leiter (1997) investigações que esclareçam essa relação entre o indivíduo e seu futuro (fazer as pessoas felizes e saudáveis) que se evidencia como direção, sentido e fonte de motivação para a ação profissional. De sorte que, ao não considerar essa variável de relação com futuro, o processo psicológico de insatisfação, desilusão e sofrimento que faz o estresse crônico se transformar em esgotamento emocional não fica esclarecido e, por conseqüência, o desenvolvimento de burnout não fica suficientemente equacionado.

Shaufeli e Buunk (2003) sustentam, da mesma forma que Maslach, que o desenvolvimento de burnout dá-se como um processo no qual o indivíduo, em função do estresse crônico laboral, é levado à exaustão emocional e, por conseqüência, à despersonalização como estratégia de defesa e, finalmente, para a diminuição da realização pessoal. Dessa forma, a mesma pergunta formulada para o modelo teórico de Maslach pode ser posta para o modelo de Shaufeli e Buunk: como ocorre de alguém em uma situação de estresse crônico no trabalho chegar ao esgotamento emocional? Shaufeli e Buunk (1993), na busca de esclarecer o desenvolvimento de burnout, centram o foco de suas análises nos estressores presentes nas relações interpessoais entre profissionais, ampliando a análise de Maslach centrada na relação entre o profissional e as pessoas assistidas. Conforme os dados empíricos verificados nos profissionais de enfermagem (Shaufeli \& Buunk, 1993), os autores sustentam que os indivíduos mais afetados pela síndrome de burnout são aqueles com alta orientação para mudança e com elevada auto-estima. Em outros termos, são os indivíduos comprometidos em produzir mudanças nas organizações em que trabalham e com fortes sentimentos de competência e valor profissional que regularmente chegam à exaustão emocional em função de estressores presentes nas relações interpessoais.

Quais são, então, as características das relações interpessoais entre os profissionais capazes de produzir uma situação de estresse crônico? Os autores observam que os 
profissionais com alta orientação para mudança quando exercem seu trabalho com alto grau de incerteza em relação a como proceder, tratar ou envolver-se com os pacientes que assistem, são levados a altos níveis de exaustão emocional. Concluem que o alto grau de incerteza (Shaufeli \& Buunk, 1993) no trabalho dos profissionais é um resultado da falta de suporte que cada profissional experimenta em relação aos demais colegas e que, por sua vez, produz tanto condutas de isolamento mútuo nas organizações em função do medo de exporse e ser tratado como incompetente, como também cria atitudes de comparação face aos demais, na intenção de resgatar a competência perdida.

Em síntese, Shaufeli e Buunk (1993) evidenciam como a falta de suporte entre os profissionais nas organizações produz uma alta incerteza em relação à melhor maneira de executar as atividades profissionais, o que, por sua vez, leva ao isolamento, ao medo da incompetência, à busca solitária de quem somente conta consigo para manter sua competência profissional e, como conseqüência desse processo, deteriora a orientação para mudança e a auto-estima, conduzindo à exaustão física e emocional.

Mas Shaufeli e Buunk (2003), tal como Maslach, não consideram em seu modelo teórico a dimensão de relação com o futuro contida nos profissionais com orientação para mudança. Não fornecem um tratamento teórico ao fato de que os profissionais mais afetados pela síndrome de burnout são justamente aqueles que fracassam na busca de, através de seu trabalho, alcançar um futuro onde as pessoas (clientes, pacientes etc.) e a organização mudem e se tornem mais saudáveis, satisfeitas, produtivas do que são no presente. Em conseqüência, Shaufeli e Buunk deixam de considerar uma variável crucial do processo de desenvolvimento de burnout, qual seja, a relação indivíduo-futuro, que torna compreensível como o estresse crônico provocado pela falta de suporte nas relações interpessoais, ao deteriorar a orientação para mudança e a auto-estima, transforma-se em burnout.

O modelo teórico de Cherniss (1993) traz, em relação às perspectivas de Maslach, Shaufeli e Buunk, contribuições importantes no esclarecimento da função crucial que ocupa o sentimento de fracasso psicológico (Cherniss, 1993) no processo de transformação do estresse crônico em burnout. Cherniss sustenta que os sentimentos de competência e eficácia para se chegar a resultados intencionados e pessoalmente significativos são uma fonte de motivação para a ação humana. E, adaptando o modelo de sucesso psicológico de Hall (Cherniss, 1993), demonstra, com base em estudos de casos individuais, que os profissionais ao não alcançarem os resultados intencionados com os quais estão comprometidos pessoalmente são levados a um sentimento de fracasso psicológico. E é esse sentimento que os faz passar do estresse à apatia, ao desinteresse total e à depreciação das recompensas intrínsecas ao trabalho realizado (educar os alunos, curar os pacientes, defender os clientes etc.). De sorte que, Cherniss contribui num aspecto fundamental para a compreensão do desenvolvimento de burnout que Maslach, Shaufeli e Buunk não tratam: demonstra como os estressores falta de suporte, falta de autonomia e sobrecarga conduzem o indivíduo ao fracasso psicológico, caracterizado pelos sentimentos de perda da competência e eficácia profissional. Sendo esse fracasso psicológico expresso pela variável diminuição da realização pessoal, capaz de exaurir emocionalmente o indivíduo e, na seqüência, levar à despersonalização.

Importante notar que o modelo teórico sustentado por Cherniss encontra nas investigações de Gil-Monte e Peiró $(1999,1997)$ uma consistente corroboração. De acordo com estes autores, os estressores ambigüidade de papel e falta de suporte modificam a competência profissional percebida e a auto-confiança, conduzindo dessa forma a uma diminuição da realização pessoal que faz o estresse tornar-se exaustão emocional. É possível depreender portanto, seja do modelo de Cherniss ou de Gil-Monte e Peiró, que as condições objetivas do trabalho com seus estressores levam a um abalo do eu (Gil-Monte \& Peiró, 1999) na sua eficácia e competência que produz a diminuição da realização pessoal e transforma o cansaço e estresse em exaustão. 
Apesar de ampliar o esclarecimento do processo de desenvolvimento de burnout ao demonstrar a relevância do sentimento de fracasso psicológico, Cherniss não aproveita e desenvolve as evidências que mostram como esse fracasso psicológico somente existe face aos resultados (futuros) intencionados e pessoalmente significativos. O autor não leva adiante a hipótese sugerida pelas evidências empíricas de que é frente a um futuro perseguido e pessoalmente significativo para alguém que o fracasso da competência e da eficácia torna-se fracasso psicológico e, portanto, capaz de desencadear burnout.

No entanto, Cherniss oferece indicações teóricas essenciais para o desenvolvimento de futuras pesquisas nessa direção. Em seu livro Beyond burnout (1995), após analisar a trajetória de vida e profissional de 26 casos individuais, constata que os indivíduos, ao início de suas carreiras, experimentavam seu trabalho como extremamente significativo. Isso se devia ao fato de estarem ligados a objetivos mais amplos e transcendentes do que as tarefas profissionais por si mesmas (Cherniss, 1995). Observa então o autor que os profissionais não se vinculavam somente às responsabilidades das pessoas que assistiam, mas também a um conjunto de ideais e propósitos (futuros) e a um conjunto de pessoas e grupos que representavam e perseguiam esses propósitos. Cherniss considera ao final do mesmo livro que o fracasso psicológico ocorrido na gênese de burnout torna-se compreensível quando relacionado ao fracasso desse significado mais amplo e transcendente que o trabalho adquire na vida das pessoas. E, dessa forma, aponta como necessário recorrer ao suporte teórico do existencialismo por ele fornecer fundamentos teóricos que permitem compreender a questão do significado mais amplo e transcendente que o trabalho assume na vida dos indivíduos.

Na perspectiva existencial desenvolvida por Pines (1993) e Pines e Aronson (1988) é possível encontrar desenvolvimentos científicos nessa direção. De acordo com Pines (1993), o trabalho na vida moderna adquire um significado existencial, ou seja, significa algo no conjunto da existência passada, presente e futura do indivíduo, que vai além da relação com as tarefas profissionais em si mesmas. E, para Pines e Aronson (1988), a raiz de burnout estaria no fracasso desse significado existencial que o trabalho adquire para um sujeito, esclarecendo que a sobrecarga, a ambigüidade de papéis, a falta de suporte e autonomia, ao inviabilizarem a realização do trabalho de professores, enfermeiros, médicos, assistentes sociais, advogados, policiais, desencadeiam um fracasso do significado existencial que essas profissões assumem na vida de cada um, gerando uma experiência de fracasso e desilusão capaz de transformar o estresse em burnout.

O modelo de Pines (1993), que esclarece o processo de desenvolvimento da síndrome de burnout, pode ser exposto da seguinte forma: no ponto de partida há objetivos e expectativas pessoais que se incluem em expectativas de grupos específicos e no universo profissional e que expressam a busca de um significado existencial do trabalho para o conjunto da vida do indivíduo. Em seguida, o confronto do indivíduo com uma realidade estressante caracterizada pela presença de características negativas (alta sobrecarga, interferências burocráticas que geram ambigüidade e conflito de papéis) e pela ausência de características positivas (falta de suporte de colegas, supervisores e falta de autonomia). Desse confronto, do indivíduo portador de um trabalho existencialmente significativo para si com uma realidade organizacional marcada por fatores estressantes, resulta que os objetivos e expectativas perseguidos não são alcançados e a experiência de fracasso do significado existencial do trabalho acontece. Desse fracasso, portanto, é que resulta a diminuição da realização pessoal, a despersonalização e o esgotamento das energias para enfrentar as situações estressantes de trabalho (Pines, 1993).

Apesar de proporcionar avanços em relação aos modelos anteriores, ao demonstrar que o fracasso psicológico ocorrido no trabalho somente pode desenvolver burnout por estar implicado com um fracasso do significado existencial do trabalho no conjunto da existência histórica do indivíduo, Pines não esclarece a dimensão crucial ocupada em seu modelo da relação do homem com seu futuro que, por sua vez, permitiria elucidar como o significado 
existencial do trabalho constitui-se, mantém-se e perde-se. Conforme o modelo de Pines (1993), se o profissional encontra-se em relação com um futuro permeado por objetivos e expectativas de ser que vão além da relação com o trabalho em si, considerar cientificamente essa dimensão do homem em relação com o futuro evidencia um aspecto fundamental para se compreender como o trabalho adquire um significado no conjunto de uma existência concreta e como seu fracasso torna-se capaz de desencadear burnout.

\section{Da síndrome de burnout à definição de projeto de ser}

Com base nesses argumentos é possível concluir que, caso essa variável da relação do homem com o futuro não seja tratada cientificamente, corre-se o risco de considerar a relação do homem com o futuro como sendo uma simples meta ou objetivo organizacional a cumprir, e não como uma dimensão crucial da existência humana concreta capaz de exercer uma função do processo de desenvolvimento de burnout. Por essa razão, a questão técnica posta por Cherniss (1995) assume uma pertinência e uma atualidade, quando considera a necessidade de recorrer às bases teóricas do existencialismo, onde a questão do significado é esclarecida em conexão com a relação do homem com o futuro. Em outros termos: tendo em vista a dimensão do futuro como estando sempre presente no processo de desenvolvimento de burnout e, ainda, considerando essa dimensão do futuro como essencial para uma compreensão significado existencial do trabalho, mostra-se teoricamente relevante para um avanço da compreensão sobre o processo de desenvolvimento de burnout a utilização da definição de projeto de ser do existencialismo de Sartre, visto que essa definição esclarece cientificamente a relação do homem com o futuro como uma dimensão temporal essencial para se compreender a ação humana como significativa.

O conceito de projeto de ser de Sartre evidencia-se como um eixo central dentro de sua obra técnica e científica dedicada à psicologia e à antropologia (Cannon, 1991; Jameson, 1985). Nesse sentido, é importante notar como Sartre desde o início de sua formação preocupou-se com o avanço científico da psicologia (Beauvoir, 1961), buscando pôr em evidência a dimensão temporal da existência humana e a função fundamental da relação do indivíduo com o futuro. É nessa perspectiva que Sartre produz A transcendência do ego (Sartre, 1992), onde trabalha a definição do ego ou personalidade, fazendo a distinção entre consciência e ego e pondo em evidência a dimensão da temporalidade psíquica. Na seqüência escreve O imaginário (1986), onde estabelece uma teoria do imaginário baseada na intencionalidade da consciência, e Esboço de uma teoria das emoções (1987), onde a relação do com homem com o futuro mostra-se uma dimensão essencial para se compreender o fenômeno emotivo. Em O ser e o nada (1986), ao estabelecer as bases ontológicas da relação homem-mundo, desenvolve sua definição de liberdade e de projeto de ser e, quinze anos mais tarde, na obra Crítica da razão dialética (1979), retomando sua definição de projeto de ser, estabelece os fundamentos para a compreensão da dinâmica dos grupos, das organizações e da história. Sartre ainda aplica seus desenvolvimentos teóricos em estudos biográficos como Saint Genet: ator e mártir (2002) e O idiota da família (1975), onde demonstra exaustivamente como um homem, ou seja, o projeto de ser de um homem, pode ser inteiramente conhecido com remissão às suas bases antropológicas, dispensando o determinismo materialista, bem como o inconsciente freudiano (Sartre, 1986).

É possível verificar como essas psicologia e antropologia desenvolvidas por Sartre têm sido objeto de estudos e aplicações em diversos campos da teoria e da prática da ciência psicológica. Nas décadas de sessenta e setenta os psiquiatras Laing e Cooper (1982), para compreender e tratar pacientes equizofrênicos e suas famílias, basearam grande parte de seu trabalho na teoria de grupos desenvolvida por Sartre na obra Crítica da razão dialética (1979). 
As pesquisas realizadas por Gaulejac (1987) na França, sobre as trajetórias profissionais e os conflitos psicológicos vividos pelos indivíduos ao saírem de sua classe e ascenderem socialmente, possuem como um de seus suportes teóricos principais a definição de liberdade e de projeto de Sartre. O trabalho de Cannon (1991) aproveita o conjunto teórico e metodológico do existencialismo de Sartre para superar a crise teórica (Cannon, 1991) presente no arcabouço psicanalítico para, desse modo, fundamentar uma outra prática psicoterapêutica. No Brasil, Moutinho (1995) demonstra como a psicologia de base fenomenológica desenvolvida por Sartre possui na definição de projeto de ser um de seus aspectos essenciais e busca esclarecer as razões da passagem feita por Sartre da psicologia para seu ensaio de ontologia. Gonçalves (1996) trabalha com a chamada psicanálise existencial, desenvolvida em O ser e o nada (Sartre, 1986), esclarecendo suas diferenças com a psicanálise freudiana, que concebe o homem determinado pelo passado ao invés de compreendê-lo em função do futuro. Schneider (2002) demonstra as perspectivas teóricas e metodológicas para a psicologia clínica presentes na psicologia desenvolvida por Sartre a partir do estudo da obra Saint Genet: ator e mártir (Sartre, 2002), e por fim, Ehrlich (2002) evidencia a contribuição da definição de projeto de ser na supressão da lacuna teórica existente na psicologia da orientação profissional em relação à dimensão do homem com o futuro. De sorte que esse conjunto de investigações permitem afirmar o aspecto essencial dentro das obras técnicas de Sartre da dimensão temporal, consubstanciada na definição do homem como projeto de ser e o quanto ela tem a contribuir no esclarecimento do homem concreto e de seus aspectos psicológicos.

Para esclarecer sinteticamente a definição de projeto de ser, é preciso considerar que Sartre (1986) parte da evidência de que qualquer ação humana nunca se limita a si mesma e remete-se sempre a algo mais amplo. Em outros termos: ele parte da verificação de que o ato humano é significativo. Isso implica em observar que o ato de trabalhar como enfermeiro, como professor ou executivo não se limita a si mesmo, mas remete a uma estrutura mais geral que lhe dá um significado: trabalhar como executiva para se tornar independente e dona de si mesma, em vez de submissa como sua mãe, ou trabalhar como professora para se tornar referência para a vida dos alunos, em vez de excluída como sua família de origem, são exemplos possíveis de se observar a partir dos casos clínicos trabalhados por Pines (2002a). A questão fundamental a ser compreendida nos limites deste artigo é que a elucidação objetiva do significado que o trabalho assume no conjunto de uma existência concreta somente mostra-se possível a partir do projeto de ser compreendido como a livre eleição que um homem faz de si mesmo dentro de condições sócio-históricas determinadas (Sartre, 1986).

Sartre demonstra que para se compreender um homem é necessário compreender seu projeto (Sartre, 1979) e, nesse sentido, é preciso começar por inverter a tese comumente aceita na psicologia de que seria o passado ou os condicionamentos precedentes que determinariam a ação. Em vez disso, uma ação humana somente é possível de ser compreendida como uma "volta do futuro em direção ao presente" (Sartre, 1986, p. 484). De sorte que "a mais rudimentar conduta humana precisa ser determinada simultaneamente em relação aos fatores reais, presentes que a condicionam e a um certo objeto futuro que ela procura engendrar. A isto chamamos Projeto" (Sartre, 1979, p. 77). A executiva investigada por Pines (2002a), em cada noite passada em claro fazendo relatórios para a empresa, busca engendrar com essa ação o futuro de ser independente, dona de si mesma. Ou ainda, a professora filha de imigrantes está orientada em cada aula que prepara no presente por um futuro em que seus alunos agradecerão os conhecimentos adquiridos. Dessa forma, o ser humano se define pelos fins que persegue (Sartre, 1986), sendo essa estrutura pro-jetiva caracterizada pela consciência de alguma finalidade que o sujeito busca alcançar como resultado de suas ações no mundo objetivo.

Compreende-se, dessa forma, que o homem é seu projeto e não um ser que tem um projeto, como se este último fosse outra coisa que a própria realidade humana em seu 
movimento concreto (Sartre, 1979). Isso significa que o ser humano se define a si mesmo como um estado perpétuo de ser-para-além-de-si-mesmo-em-direção-a (Sartre, 1979), pondo em evidência que o futuro em direção ao qual um indivíduo se move e que busca engendrar como resultado de suas ações e de seu trabalho, não apenas cria novos objetos ou situações no mundo objetivo, mas faz dessa busca "uma incessante produção de si mesmo pelo trabalho e pela ação" (Sartre, 1979, p. 81). O homem, desse modo, é o futuro para o qual se elege e projeta e alcançar essa realidade futura pro-jetada o faz tornar-se determinada pessoa em detrimento de outras possíveis. Alcançar o reconhecimento de seus alunos para a professora filha de imigrantes estudada por Pines (2002a) é tornar-se alguém que inspira a vida dos outros e, assim, é fazer-se respeitada ou, ainda, alcançar um cargo na diretoria para a executiva investigada por Aubert (2002) é tornar-se um orgulho de mulher por chegar aonde sua mãe e avó não chegaram. Da mesma forma, receber o descrédito dos alunos e dos colegas de trabalho é tornar-se aquela que não inspira a ninguém e assim fazer-se a rejeitada e excluída como sua família de origem. Ou ainda, para a executiva, não alcançar sua promoção, é fazer-se a fracassada por não ter ido além das demais mulheres de sua família. Dizer então, que um homem é seu projeto significa afirmar a íntima e inseparável conexão entre presente e futuro e esclarecer a dimensão futura como aquela que proporciona o significado à ação presente: "aliás, dizer de um homem o que ele 'é' é dizer ao mesmo tempo o que ele pode e reciprocamente" (Sartre, 1979, p. 79).

O homem ser seu projeto implica também em compreender um outro aspecto crucial que se caracteriza pela unidade dialética entre os sujeitos e as condições materiais. As condições materiais em que se encontra um indivíduo circunscrevem seu âmbito de possibilidades, como esclarece Sartre (1979), sendo que tal âmbito de possibilidades depende, por sua vez, da realidade sócio-histórica: a falta de suporte de colegas ou chefias está ligada a uma gerência das organizações que prioriza a serialização e a burocracia em detrimento da formação de grupos que, por sua vez, relaciona-se a um contexto histórico onde o individualismo e a concorrência no mercado são preponderantes. Ou, ainda, o aumento da carga de trabalho para um gerente depende da realidade sócio-histórica em que os recursos econômicos são cada vez mais direcionados para os ganhos de capital financeiro e não para o desenvolvimento das possibilidades humanas. Logo, é dentro de um âmbito de possibilidades determinadas pelas condições materiais e históricas que a dimensão do futuro, como o campo de possibilidades para um indivíduo projetar-se e produzir a si mesmo, precisa ser compreendida (Sartre, 1979). De sorte que "a mais individual das possibilidades nada mais é que a interiorização e o enriquecimento de uma possibilidade sócio-histórica" (Sartre, 1979, p. 48), evidenciando, dessa forma, a existência de uma unidade indissolúvel entre o sujeito que se elege e se projeta-em-direção-a e o mundo objetivo que se organiza de acordo com certas condições sócio-históricas.

O homem ser seu projeto implica, por fim, em compreender um último aspecto: que o ultrapassamento constante da realidade presente em direção ao futuro projetado não se reduz às condições materiais dadas pelas organizações e pela sociedade: é preciso considerar que o homem precisa ultrapassar a todo instante seu passado de infância e juventude vivido concretamente a partir do sociológico familiar de origem (Sartre, 1979). Retomando o exemplo dado por Pines (2002a), a título de ilustração, é possível observar que a professora projeta-se para o futuro na busca de se tornar alguém de referência para a vida de seus alunos ultrapassando, através de seu trabalho, o passado familiar de pobreza e exclusão. Dessa maneira, o passado, como a realidade das relações recíprocas do indivíduo com seu grupo de gênese, evidencia-se como um conjunto de contradições que o sujeito, ao escolher seu futuro (Sartre, 1986) e projetar-se em direção as suas possibilidades, precisa constantemente superar. Logo, o significado que o trabalho adquire no conjunto de uma existência individual, tal como constataram Pines (1993) e Cherniss (1995), somente torna-se compreensível na medida em que se elucida o projeto de ser para o qual o sujeito elegeu-se e no qual está 
lançado, num esforço constante de ultrapassamento tanto das condições sócio-históricas presentes, quanto das contradições sociológicas passadas.

\section{Relações entre projeto de ser e a síndrome de burnout}

A partir dessas breves considerações sobre a definição de projeto de ser, um primeiro aspecto a ser destacado de suas relações com a síndrome de burnout é de que o trabalho humano caracteriza-se essencialmente como projeto e não como respostas a estímulos contingentes. A ação profissional, dessa forma, não é simplesmente uma resposta às altas demandas e aos poucos recursos existentes no ambiente de trabalho. Ela visa fundamentalmente a produção de uma determinada realidade futura que o indivíduo busca instaurar no mundo objetivo. Como sustenta Sartre, "este projeto tem um sentido, não é a simples negatividade, fuga: por ele o homem visa à produção de si mesmo no mundo como certa totalidade objetiva" (Sartre, 1979, p. 117). Nos estudos no campo da saúde mental e trabalho, são várias as evidências empíricas que mostram essa característica antropológica da ação e do trabalho humanos. Seligmann-Silva (1994), ao estudar os trabalhadores da indústria, verificou nos sujeitos entrevistados como a relação com a realidade fatigante do trabalho era ultrapassada em direção a uma determinada possibilidade futura que dava sentido à tarefa exercida: para alguns era a busca da casa própria para, assim, tornarem-se determinados sujeitos que providenciaram à família uma garantia material de vida que eles próprios não tiveram; para outros, o projeto era ter seu próprio negócio e, dessa forma, tornarem-se empreendedores, donos de sua própria vida. O caso de uma policial discutido por Sampaio e Carneiro (1997) também permite identificar um projeto de ser alguém que protegeria as pessoas e, dessa forma, tornari-sea forte e corajosa dentro de seu grupo familiar. $\mathrm{Ou}$, ainda, o caso de um vigia noturno estudado por Lima (2002), no qual todos seus empregos ou empreendimentos profissionais evidenciavam-se como permeados pelo projeto de se tornar "gente de respeito", "com coragem para trabalhar", "não ser preguiçoso" para, dessa forma, superar a escassez material (Lima, 2002, p. 217). É possível compreender, a partir dessas evidências, como as altas demandas e os poucos recursos existentes numa dada organização tornam-se estressantes à medida que alienam o sujeito dos fins que dão sentido à sua ação profissional e ao seu trabalho. Em outros termos: "a possibilidade permanente de que um fim seja transformado em ilusão caracteriza o campo social e os modos de alienação (...) Melhor ainda, as noções de alienação e de mistificação não têm precisamente sentido senão na medida em que roubam os fins e os desqualificam" (Sartre, 1979, p. 124).

Um segundo aspecto que convém destacar ao se pensar a relação entre o projeto de ser e a síndrome de burnout é que o primeiro caracteriza-se como unificador da totalidade da história individual, o que permite compreender as diversas ações e projetos profissionais como meios na realização de uma totalidade mais ampla que é justamente o projeto de ser (Ehrlich, 2002). Isso significa que compreender o projeto de ser de alguém implica em compreender a escolha original (Ehrlich, 2002; Sartre, 1986) que o sujeito fez de si mesmo no mundo, sendo as mais variadas ações, escolhas ou empreendimentos realizados nos diversos momentos de uma vida, um enriquecimento ou desvio dessa escolha ou projeto originais:

E assim capto-me, efetivamente, neste momento em que escrevo: não sou a simples consciência perceptiva de minha mão que traça signos sobre o papel; estou muito a frente desta mão, até o término do livro e até a significação do livro - e da atividade filosófica em geral - na minha vida; e no marco deste projeto, quer dizer, no marco do que sou, se inserem certos projetos em direção a possibilidades mais restritas, como as de expor uma idéia de tal ou qual maneira, ou cessar de escrever um momento, ou folhear uma obra em que busco tal ou qual referência, etc. Agora bem, seria errôneo acreditar 
que a essa eleição global corresponde uma consciência analítica e diferenciada (Sartre, 1986, p. 488).

Assim como o ato de traçar palavras sobre o papel remete ao término do livro (futuro), que, por sua vez, remete ao projeto de ser um determinado intelectual e à significação dessa realização futura na totalidade dessa vida singular, da mesma forma, o ato de trabalhar fazendo rondas na escola (Sampaio \& Carneiro, 1997) remete ao projeto original de ser, através da polícia, uma mulher forte, corajosa e protetora dos outros, que, por sua vez, unifica sua história passada, presente e futura como filha de um militar corajoso, como esposa de um membro da polícia e como mãe exemplar para seus filhos. É possível compreender, dessa forma, como o trabalho realizado por um indivíduo com seus empreendimentos e projetos profissionais possui uma função psicológica na totalidade da personalidade, à medida que a atividade profissional se integra numa estrutura mais ampla que é justamente o projeto de ser. De sorte que, mostra-se como um aspecto fundamental para compreender o desenvolvimento da síndrome de burnout identificar a função do trabalho e do projeto profissional no conjunto de um projeto de ser singular para, dessa forma, tornar compreensível como os estressores crônicos laborais podem ser capazes de conduzir a desvios e fracassos do projeto de ser e, dessa forma, produzir fracassos psicológicos incapacitantes, à medida que alcançam a totalidade do sujeito e não unicamente o seu perfil profissional.

A definição de projeto de ser permite considerar um terceiro aspecto no que diz respeito às suas relações com o desenvolvimento de burnout, qual seja, a questão do desejo presente na motivação profissional. Como já foi exposto, um fato regularmente encontrado nos profissionais que se esgotam, que se despersonalizam e perdem a satisfação pessoal é o de terem, em algum momento de suas carreiras, forte motivação e comprometimento profissional, estando, portanto, a relação com o trabalho não no plano da obrigação compulsória, mas sim no plano de algo satisfatório e desejável. A definição de projeto de ser, permite esclarecer que essa motivação para a ação e para o trabalho humano dá-se em função da realização de um futuro projetado do qual o indivíduo encontra-se em falta ou necessitado (Sartre, 1986) e não como uma força inconsciente resultante da energia pulsional, como defende a posição metafísica freudiana (Cannon, 1991; Sartre, 1986):

Mas se é assim, comprovamos que a ação implica necessariamente como sua condição o reconhecimento de um <desiderátum $>$, quer dizer, de uma carência objetiva, ou bem, de uma negatividade (...) mas esse reconhecimento não pode ser a pura representação de uma possibilidade, senão a captação de um possível desejável e não realizado (Sartre, 1986, p. 460).

É do projeto de ser uma policial corajosa e forte, que existe no mundo para proteger as pessoas, que resulta o desejo de fazer a ronda na escola, de enfrentar assaltantes para, dessa forma, suprimir a falta de segurança existente na realidade objetiva; é do projeto de ser "gente de respeito", "com coragem para trabalhar" e ultrapassar a escassez material (Lima, 2002) que resulta o desejo e a motivação de enfrentar um trabalho penoso como vigia noturno e assim superar a falta advinda da escassez material; é do projeto de ser alguém com seu próprio negócio e tornar-se empreendedor e dono de sua própria vida que resulta a motivação para aprender, o desejo de poupar ou de suportar longas jornadas no caso dos metalúrgicos estudados por Seligmann-Silva (1994). E, por fim, é do projetar-se para o futuro na busca de tornar-se alguém de referência para a vida de seus alunos e ultrapassar o passado familiar de pobreza e exclusão que a professora, objeto de investigação de Pines (2002a), deseja preparar as aulas e capacitar seus alunos.

Assim, o desejo expressa, por sua estrutura mesma, a relação do homem com um ou mais objetos no mundo, e é um dos aspectos do ser-no-mundo. Desde este ponto de vista, não parece que esta relação vem a ser de um único tipo. Somente para abreviar falamos de 
$<$ desejo de algo $>$. Na realidade, numerosos exemplos empíricos mostram que desejamos possuir tal objeto, fazer tal coisa, ser alguém. Se desejo este quadro significa que desejo apoderar-me dele. Se desejo escrever um livro ou passear, significa que desejo fazer um livro ou dar um passeio (Sartre, 1986, p. 599).

Visto que o desenvolvimento da síndrome de burnout envolve aqueles profissionais motivados e comprometidos com sua profissão e seu trabalho, e que progressivamente, vão exaurindo-se, descomprometendo-se e frustrado-se, tal processo indica um desvio ou uma perda do projeto de ser original, que, por sua vez, vai afetando o desejo de fazer tal trabalho e de ser determinado sujeito através do trabalho que realiza. O exemplo da policial estudada por Sampaio e Carneiro (1997) pode ser esclarecedor a esse respeito: foi estuprada no seu ambiente de trabalho, na seqüência foi desgastando-se com os policiais corruptos que "entravam na psicologia do criminoso" (Sampaio \& Carneiro, 1997), até chegar um momento em que desconfiou que seu pai e seu marido eram também corruptos. A cada um desses acontecimentos sócio-históricos corresponde um abalo no projeto e no desejo de ser: ao ser estuprada ficou segurando a esperança para não perder a paixão pela polícia (Sampaio \& Carneiro, 1997) e após quatro anos desgastando-se com os policiais corruptos e passar a desconfiar que seu pai e seu marido caíram na rede de corrupção, não suportou mais continuar a ser policial, pedindo afastamento do trabalho e desenvolvendo um quadro psicológico severo (Sampaio \& Carneiro, 1997). O futuro possível e desejável de ser policial foi progressivamente sendo abalado e a escolha ou projeto original de ser corajosa e forte em seu grupo familiar através da policia foi se tornando cada vez mais impossível de realizar-se. Dessa forma, o eixo totalizador de uma história individual - o projeto de ser - vai sofrendo com toda espécie de desvios, de obstáculos não superados e, como sua outra face, o desejo de ser determinada profissional e de fazer-se mulher, mãe e filha corajosa dentro de seu grupo vai se perdendo. O futuro que motiva o comprometimento na profissão é perdido, o projeto que gera o desejo pelo trabalho inviabiliza-se: resta o fardo de um trabalho sem sentido, a frustração por um projeto e desejo de ser não realizados e o descomprometimento com um futuro não mais possível.

Um último aspecto que, nos limites deste artigo, convém destacar da relação entre projeto de ser e síndrome de burnout diz respeito à implicação dialética entre a objetividade das condições organizacionais e de trabalho e a singularidade humana compreendida como projeto de ser. A definição antropológica do ser humano como um ser que age no mundo objetivo transcendendo-se em direção a seus possíveis permite considerar as relações da individualidade com as variáveis estressantes laborais sem perder nenhum dos pólos dessa relação na análise do processo de desenvolvimento de burnout. Dessa forma, a sobrecarga de trabalho, a pressão de tempo, a falta de suporte e de autonomia nas relações de trabalho são condições objetivas dadas por fatores econômicos, administrativos e gerenciais que definem toda uma dinâmica organizacional estressante, característica do mundo do trabalho no atual contexto histórico e que estabelece determinado campo de possibilidades. Porém, essas variáveis objetivas estressantes remetem à função que cada uma delas exercem no movimento concreto de um profissional em direção ao futuro projetado. A troca de um gerente privou drasticamente as possibilidades de futuro profissional dentro da empresa que uma executiva estudada por Aubert (2001) tinha até determinado momento de sua carreira. Um futuro que se relacionava com a função do trabalho para as mulheres de seu sociológico familiar e, no momento em que tal executiva compreendeu-se impossibilitada pelas condições objetivas de viabilizar seu projeto e desejo de ser, desespera-se com a solidão de quem perdeu sua função para os outros, dentro e fora do trabalho: "neste nível posso notar que sua solidão não é um estatuto inerte (...) senão que de fato está vivida no projeto de cada um como sua estrutura negativa. Ou se, se quiser, a solidão de um organismo como impossibilidade de unirse aos outros" (Sartre, 1979, p. 396). Dessa forma, o fracasso ou desvio de um projeto de ser remete às estruturas objetivas e sociais para as quais um sujeito se encontra pro-jetado, e, na 
mesma medida, todo o conjunto de estruturas objetivas e estressoras de uma realidade organizacional somente ganha sua significação quando remetidas ao projeto de cada um. Como afirma Sartre (1968) em um de seus primeiro trabalhos técnicos:

Eis-nos libertos de Proust! Libertos ao mesmo tempo da <vida interior >: em vão procuraríamos como Amiel, como uma criança a quem se beija o ombro, as carícias, os carinhos de nossa intimidade, por que, no fim das contas, tudo está fora, tudo até nós próprios: fora, no mundo, entre os outros. Não é em nenhum refúgio que nos descobriremos: é na rua, na cidade, no meio da multidão, coisa entre as coisas, homem entre os homens (p. 31).

\section{Considerações finais}

Muito se tem estudado sobre as correlações entre as variáveis estressoras laborais e a síndrome de burnout, o que permite demarcar as características essenciais desse fenômeno psicológico, bem como, determinar certo conjunto de fatores organizacionais que o desencadeiam. Mas, como sustentam Maslach, Shaufeli e Leiter (1993), investigações de corte transversal ou sincrônico não permitem apreender a etiologia de burnout e seu processo de desenvolvimento.

De sorte que, para conhecer o processo de desenvolvimento da síndrome de burnout é preciso investigações longitudinais ou diacrônicas que, ao longo de um processo temporal e histórico, verifiquem como se articulam e se determinam as condições objetivas de vida e de trabalho e os processos psicológicos. As evidências proporcionadas por investigações diacrônicas apontam para o fato de que o processo de transformação do estresse crônico em burnout implica regularmente em uma experiência de fracasso. Em Maslach (1978) tal evidência aparece como o fracasso do profissional em fazer a vida das pessoas com quem escolheu trabalhar mais feliz e saudável. Em Shaufeli e Buunk (1993) evidencia-se como o fracasso da orientação para a mudança e da auto-estima. Já em Cherniss (1993), como o fracasso psicológico por não se alcançar os resultados intencionados e significativamente importantes e em Pines (1993) o fracasso é do significado existencial que o trabalho assume dentro de uma totalidade histórica e individual.

A contribuição da definição de projeto de ser para o desenvolvimento da síndrome de burnout consiste justamente em permitir compreender concreta e objetivamente esse fracasso humano no trabalho e como é possível, a partir dessa experiência de fracasso, desencadearem-se os sintomas de burnout. É um homem em sua totalidade que fracassa, na medida em que a significação de um projeto profissional advém do projeto de ser. Portanto, o fracasso no perfil profissional somente mostra-se capaz de desencadear a síndrome de burnout quando, e somente quando, o futuro possível e desejado para o qual o sujeito elegeu-se e está projetado é perdido.

A definição de projeto de ser mostra-se relevante também por permitir compreender que esse fracasso não se reduz a uma história concreta e individual, mas a um fracasso das organizações no gerenciamento das relações de trabalho e da produtividade. Pois, cada vez mais, ao se aumentar as demandas e diminuir os recursos, tem-se estabelecido um conjunto de condições objetivas produtoras de serialização e solidão (Sartre, 1979), que alienam os indivíduos em relação a seu futuro desejável e os conduz, por razões de subsistência material, a aceitarem toda espécie de desvios e desistências em relação a seus projetos originais.

Portanto, a definição do ser humano como projeto de ser proporciona um avanço científico importante na compreensão do desenvolvimento da síndrome de burnout, pelo fato 
de permitir trabalhar com uma variável essencial nesse processo, qual seja, a relação do homem com o futuro. E, dessa forma, tornar compreensível a função dessa dimensão temporal na constituição do significado que o trabalho adquire para os indivíduos, bem como, verificar a dialética existente entre as condições estressoras laborais na atualidade e o fracasso do projeto de ser. Torna-se possível, assim, apreender elementos fundamentais para uma compreensão das relações entre o fracasso do futuro projetado, a perda do significado existencial do trabalho e as variáveis estressoras organizacionais no mundo atual e, assim, avançar no equacionamento teórico sobre o desenvolvimento da síndrome de burnout.

\section{Referências}

Antunes, R. (1999). Os sentidos do trabalho. São Paulo: Boitempo.

Aubert, N. (2001). A neurose profissional. In J.-F. Chanlat (Org.), O indivíduo na organização: dimensões esquecidas. (vol. 2, pp. 163-194). São Paulo: Atlas.

Beauvoir, S. (1961). Na força da idade. São Paulo: Difel.

Benevides-pereira. A. M. (2002). Burnout: quando o trabalho ameaça o bem-estar do trabalhador. São Paulo: Casa do Psicólogo.

Cannon, B. (1991). Sartre and psychoanalysis: an existentialist challenge to clinical metatheory. Kansas: University Press of Kansas.

Carlloto, M. S. (2002). Síndrome de burnout e a satisfação no trabalho: um estudo com professores universitários. In A. M. Benevides-Pereira (Org.), Burnout: quando o trabalho ameaça o bem-estar do trabalhador (pp. 187-212). São Paulo: Casa do Psicólogo.

Cherniss, C. (1995). Beyond burnout. New York: Routledge..

Cherniss, C. (1993). Role of professional self-efficacy in the ethiology and amelioration of burnout. In W. Shaufeli, C. Maslach \& T. Marek, (Orgs.), Professional burnout: recent developments in theory and research (pp. 135-150). Philadelphia: Taylor \& Francis.

Codo W. (1999). Educação, carinho e trabalho. Petrópolis: Vozes.

Dal Rosso, S. (2004). Dilemas do tempo: o tempo de trabalho no brasil e no mundo globalizado. In L. Dowbor, O. Furtado, L.Trevisan \& H. Silva (Orgs.), Desafios do trabalho (pp. 47-62). Petrópolis: Vozes.

Ehrlich, I. F. (2002). Contribuições do projeto de ser em Sartre para a psicologia de Orientação Profissional. Dissertação de Mestrado, Departamento de Psicologia, Universidade Federal de Santa Catarina, Florianópolis.

Farber, B. A. (1984). Stress and burnout in suburban teachers. Journal of Educational Research, 77, 325-331.

Freudenberguer, H. (1987). L'epuisement professionnel: la brulure interne. Québec: Gaétan Èditeur.

Freudenberger, H. (1974). Staff burnout. Journal of Social Issues, 30 (1), 159-165.

Gaulejac, V. (1987). La neurose de classe. Paris: Hommes \& Groupes éditeurs.

Gil-monte, P. (2003). El síndrome de quemarse por el trabajo (síndrome de burnout) en professionals de enfremaria. Revista Eletrônica Interação Psy, 1 (1), 19-33.

Gil-Monte, P. \& Peiró, J. M. (1999). Perspectivas teóricas y modelos intrepretativos para el estúdio del síndrome de quemarse por el trabajo. Anales de Psicología, 15 (2), 261-268.

Gil-Monte, P. \& Peiró, J. M. (1997). Desgaste psíquico en el trabajo: el síndrome de quemarse. Madri: Síntese.

Gonçalves, C. S. (1996). Desilusão e história na psicanálise de J.-P. Sartre. São Paulo: Nova Alexandria. 
Harvey, D. (1989). A condição pós-moderna. São Paulo: Atlas.

Jameson, F. (1985). Marxismo e forma. São Paulo: Hucitec.

Jardim, S. R., Silva Filho, J. F. \& Ramos, A. (2004). O diagnóstico de burnout na atenção em saúde mental dos trabalhadores. In R. Araújo, M. F. Alberto, M. Y. Neves \& M. Athayde (orgs.), Cenários do trabalho: subjetividade, movimento e enigma (pp. 73-87). Rio de janeiro: DP\&A.

Laing, R. \& Cooper, D. (1982). Razão e violência: uma década da filosofia de Sartre (1951-1960). Petrópolis: Vozes.

Leiter, M. (1993). Burnout as a development process: consideration of models. In W. Shaufeli., C. Maslach. \& T. Marek (Orgs.). Professional burnout: recent developments in theory and research (pp. 237-250). Philadelphia: Taylor \& Francis.

Lee, R. T. \& Ashforth, B. E. (1996). A meta-analytic examination of the correlates of the three dimensions of job burnout. Journal of Applied Psychology, 81 (2), 123-133.

Maslach, C. (1978). The client role in staff bunout. Journal of Social Issues, 34 (4), 111-124.

Maslach, C. (1993). Burnout: a multidimensional perspective. In W. Shaufeli, C. Maslach \& T. Marek (Orgs.), Professional burnout: recent developments in theory and research (pp. 19-32). Philadelphia: Taylor \& Francis.

Maslach, C. \& Jackson, S. (1981). The meansurament of experienced burnout. Journal of Occupational Behaviour, 2, 99-113.

Maslach, C. \& Leiter, M. P. (1997). Trabalho: fonte de prazer ou desgaste? São Paulo: Papirus.

Maslach, C., Shaufeli, W. \& Leiter, M. (2001). Job burnout. Anual Review of Psychology, 52, 397-422.

Moutinho, L. D. (1995). Sartre: psicologia e fenomenologia. São Paulo: Brasiliense.

Pines, A. (1993). An existential perspective. In C. Maslach, W. Shaufeli \& T. Marek (Orgs.), Professional burnout: recent developments in theory and research (pp. 33-52). Philadelphia: Taylor \& Francis.

Pines, A. (2002a). A psychoanalytic-existential approach to burnout: demonstrated in the cases of a nurse, teacher and a manager. Psychotherapy: Theory, Research, Practice, Training, 39 (1), 103-113.

Pines, A. (2002b). The female intrepreneur: burnout treated using a psychodynamic existential approach. Clinical Case Studies, 1 (2), 170-180.

Pines, A. \& Keinan, G. (2005). Stress and burnout: the significant difference. Personality and Individual Differences, 39, 625-635.

Pines, A. \& Aronson, E. (1988). Career burnout: causes and cures. New York: Free Press.

Sartre, J.-P. (1986). El ser y la nada. Buenos Aires: Losada.

Sartre, J.-P. (1979). Critica de la razón dialectica (Tomo I). Buenos Aires: Losada.

Sartre, J.-P. (1992). La trancendence de l'ego. Paris: Librarie Philosophique, J. Vrin.

Sartre, J.-P. (1987). Bosquejo de una teoria de las emociones. Madrid: Alianza Editorial.

Sartre, J.-P. (1996). O imaginário. São Paulo: Ática.

Sartre, J.-P. (1975). El idiota de la família (Tomo I). Buenos Aires: Tiempo Contemporâneo.

Sartre, J.-P. (2002). Saint Genet: ator e mártir. Petrópolis: Vozes.

Sartre, J.-P. (1968). Uma idéia fundamental na fenomenologia de Husserl: a intencionalidade. In situações I (pp. 28-31). Lisboa: Europa-América.

Schneider, D. (2002). Novas perspectivas em psicologia clínica: um estudo a partir da obra "Saint Genet: comèdien et martir" de Jean-Paul Sartre. Tese de Doutorado, Programa de Pós-Graduação em Psicologia Clínica, Pontifícia Universidade Católica de São Paulo, São Paulo.

Seligmann-Silva, E. (1996). Psicopatologia do trabalho. In R. Mendes (Org.), Patologias do trabalho (pp. 289-310). São Paulo: Ateneu. 
Shaufeli, W. \& Bunnk, B. (2003). Burnout: an overview of 25 years of reseach and theorizing. In M. J. Schabracq, J. A. M. Winnubst \& C. L. Cooper (Orgs.), The Handbook and Health Psychology (pp. 383-425). Nova York e Londres: J. Wiley \& Sons.

Shaufeli, W. \& Buunk, B. (1993). Burnout: a perspective from social comparison theory. In C. Maslach, W. Shaufeli \& T. Marek (Orgs.), Professional burnout: recent developments in theory and research (pp. 53-73). Philadelphia: Taylor \& Francis.

Shaufeli, W., Maslach, C. \& Marek, T. (1993). Professional burnout: recent developments in theory and research. Philadelphia: Taylor \& Francis.

Tamayo, M. \& Tróccoli, B. (2002). Burnout no trabalho. In A. M. Mendes, L. O. Borges \& C. Ferreira (Orgs.), Trabalho em transição, saúde em risco (pp. 43-63). Brasília: UnB.

Taris, T., Le Blanc, P., Shaufeli, W. \& Schreurs, J. (2005). Are there relationships between the dimension of the Maslach Burnout Inventary? A review and two longitudinal test. Work $\mathcal{E}$ Stress, 19 (3), 238-255.

Winnubst, J. (1993). Organizational structure, social suport, and burnout. In C. Maslach, W. Shaufeli \& T. Marek (Orgs.), Professional burnout: recent developments in theory and research (pp. 151-162). Philadelphia: Taylor \& Francis.

\section{Endereço para correspondência}

feir@uol.com.br, jczanelli@terra.com.br 